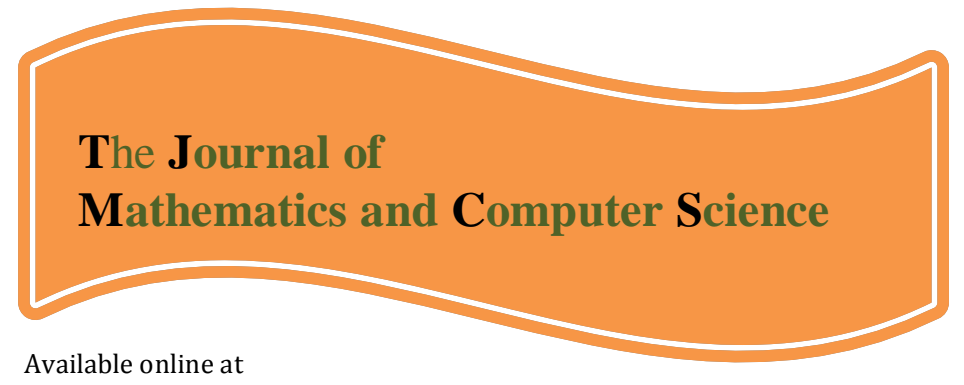

\title{
http://www.TJMCS.com
}

The Journal of Mathematics and Computer Science Vol .2 No.4 (2011) 619-630

\section{Using the Fuzzy AHP methodology in Customer's Purchasing Decision-making Process based on Marketing Mix (4Ps)}

\author{
Basirat Baygi.Mojtaba ${ }^{1,}{ }^{*}$, Emam.Seyed Reza ${ }^{2}$ \\ Shomal University, Amol, Iran, moj.basir@gmail.com \\ Shomal University, Amol, Iran, sre4046@gmail.com
}

Received: August 2010, Revised: November 2010

Online Publication: January 2011

\begin{abstract}
In purchasing process, whether in traditional or online, we face the problem of comparison and decisionmaking. Also given the fact that the main criteria which are considered by most customers in purchasing process are marketing mix (4Ps), so we take into consideration these criteria as the main criterion. Moreover, lack of certainty and definability of these criteria in fuzzy form lead us to model customer's purchasing decision-making process by using the fuzzy AHP methodology.
\end{abstract}

Keywords: Fuzzy AHP, Marketing Mix (4Ps), Customer's Purchasing Decision-Making Process

\section{INTRODUCTION :}

We are face decision-making and selecting (goods) during the day and do it continously in our life. In decision-making issue, we always face choosing one option from various options as related criteria and then we make a decision. One of the aspects of decision-making which people, organizations and managers of industrial plants encounter is decision-making about purchasing required goods and

\footnotetext{
${ }^{1, *}$ Corresponding author: Shomal university, Amol, Iran; student of MA in industrial engineering; system management and productivity.

${ }^{2}$ Shomal University, Amol, Iran; Student of MA in industrial engineering; system management and productivity.
} 
equipment. Estimated criteria in this process have been considered in numerous studies. [1] In purchasing process, criteria are different from buyer and seller's point of view and each of them try to maximise their profit rate, and criteria which are commonly considered between them is called marketing mix which expressed by Kotler and Borden in 1964. [2] After that, many other people did some research in this respect. [3] other people examined the criteria of marketing mix and considered those criteria for different times . [4]. But as regards to all studies and research which have been done, it can be observed that the only criteria which is expressed and estimated in all studies and research is marketing mix (4Ps). Buyers and customers most consider these criteria in other aspects and based on them, they decide about purchasing. These criteria are just price, quality characteristics or product, purchasing place and promotion. Also research have been done regarding using method and degree of importance of these criteria and transposition of these criteria estimations of options and decision-making in purchasing issue are explained.[5] Now regarding the uncertainty of these criteria and also considering that these criteria should be estimated in ranges and limits which are present through different sellers, they can be represented in fuzzy form and decisions are made based on these fuzzy criteria.

Finally, there are different prices, different qualities and features, various supply places, numerous services and side advantages for a certain or special goods which make some problems decisionmaking purchasing suitable goods. By considering the high level of uncertainty and fuzziness of the criteria the problem of decision-making is doubled. Our suggested method for solving this problem is to use FAHP(Fuzzy AHP)technique, which based on the decision-maker can have the best selection.

The following chapter, the suggested model and one operational case of purchasing decision-making are presented.

\section{Proposed model :}

For price as a criteria, which is considered as the most important parametere in decision-making for purchasing, it can be expressed that regarding variation of prices and also putting them in a span, it is defined in the form of a triangular fuzzy number. Also it can be noted that the price which has an important role for decision-maker, sometimes is changeable with regards to other features presented, but it has a certain and acceptable span for decision-maker, E.g, this definition has been considered in works that have been done for presenting intelligent (automative) purchasing agent. [6] 


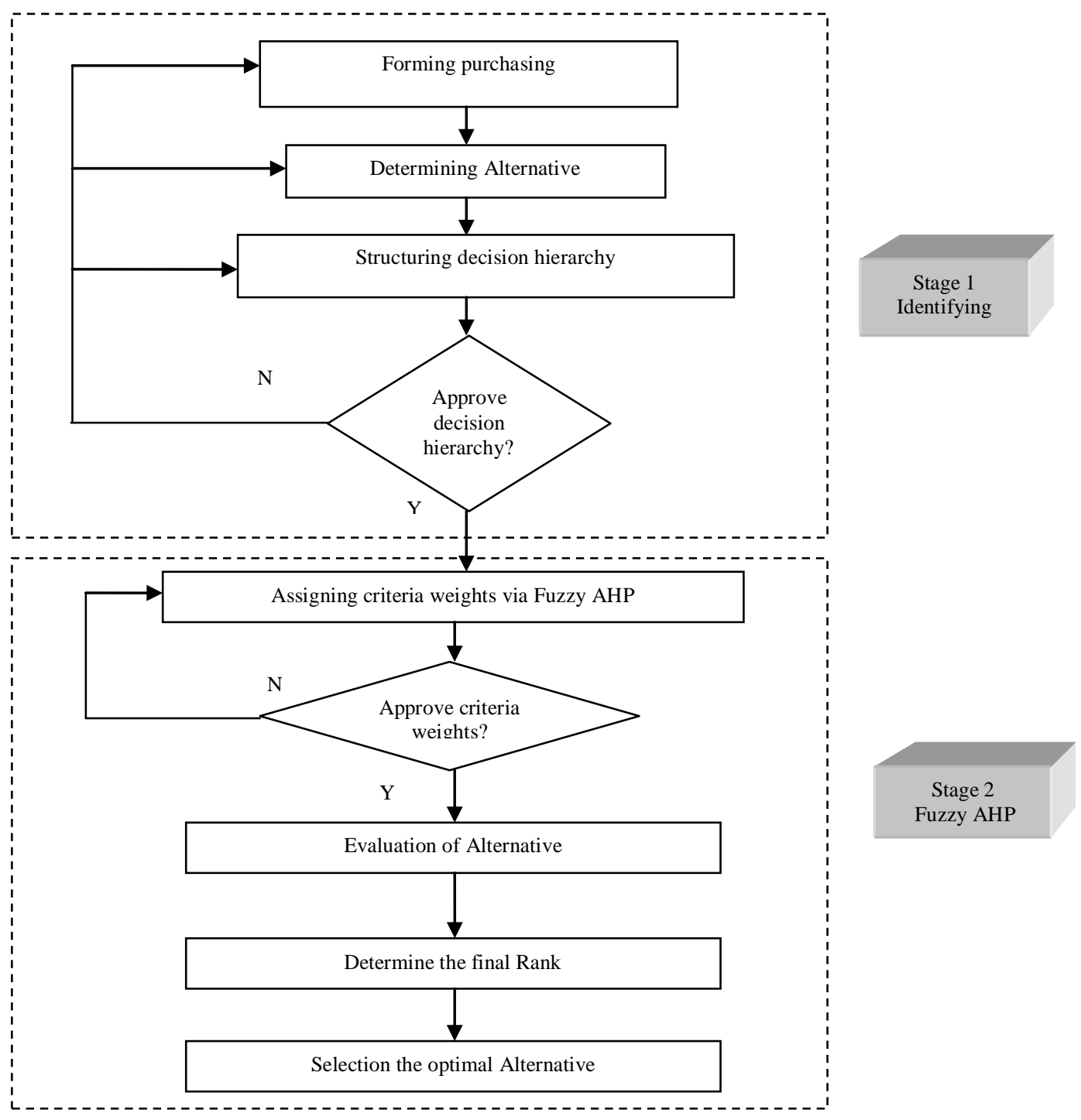

Figure 1 : Schematic diagram of the proposed model for selection.

The same argumentation also can be expressed about other criteria considering its uncertain state and available conditions in dominant environment at purchasing issue. About the product features the main objective which is considered is the good's quality.[7],[8] . By expressing our qualitative issues in this study in fuzzy form and by considering their importance in decision-making hierarchy, we get to estimation.

But about the place of purchasing the goods, distance of supply places and the time taken for customers to

recieve the goods should be considered. Because of the dependence of the criteria to the very important and effective factor of lead time(LT) and because this factor is fuzzy, the goods supply site can be considered in triangular fuzzy number and it can be used in decision-making hierarchy structure. 
As fir side effects or promotion, some factors such as flexibility in giving services, gurantee, receiving and installation costs, etc. are effective and should be considered in fuzzy form.

To have suitable selection in purchasing process, we should consider 2 steps. In below the first step, we should identify available options and also we should determine criteria, based on which decisionmaking is done and which are here the same (4Ps) criteria. Then we should form decision hierarchy and in the case of accepting the steps mentioned above, we can consider the next step which is determining of the best option by using fuzzy AHP technique. (Fig.1).

\section{Fuzzy AHP Methodolgy :}

The Analytic Hierarchy Process (AHP) is a powerful and flexible decision-making process (Saaty, 1980)[9] to help Decision-makers set priorities and make the best decision when both qualitative and quantitative aspects of a decision need to be considered. By reducing complex decisions to a series of one-on-one comparisons, then synthesizing the results, many researchers have concluded that AHP is a useful ,practical and systematic method for rating (Barbarosoglu and Yazgac, 1997)[10]; it has certainly, been applied successfully. However, in many practical cases the human preference model is uncertain and decision-makers might be reluctant or unable to assign exact numerical values to the comparison judgments. For instance, when evaluating different purchases, the decision-makers are usually unsure about their level of preference due to incomplete and uncertain information about possible purchases and their performances. Since some of the purchases evaluation criteria are subjective and qualitative, it is very difficult for the decision-maker to express the strength of his / her preferences and to provide exact pair-wise comparison judgments. For this reason, a methodology based on fuzzy AHP can help us to reach an effective decision (Bellman and Zadeh, 1970)[11]. By this way we can deal with the uncertainty and vagueness in the decision process .

Fuzzy AHP consists of deriving the local priorities from these fuzzy preference ratios, which are subsequently aggregated to form the global priorities. The fuzzy AHP computes fuzzy priorities based on arithmetic operations for fuzzy triangular (or trapezoidal) numbers. To be able to use the fuzzy arithmetic operations, specific assumptions on the forms of membership functions are required. However, the most important criticism directed at fuzzy arithmetic operations is their failure to address the issue of consistency. There is no explicit articulation on what would constitute an inconsistent comparison matrix within the fuzzy AHP context and, equally important, on how inconsistent information should be handled .

Lacking a mechanism to exclude inconsistent data, fuzzy priorities so obtained are likely to be flawed (Zimmerman, 1991[12]; Buckley, Feuring, and Hayashi, 2001)[13]. In addition to combining the AHP approach with other methods, Zaim et al. (2003)[14] has discussed fuzzy analytic hierarchy based approach for purchase selection in the area of marketing. Chen et al. (2006)[15] also employed hierarchical model using triangular fuzzy numbers to deal with purchase selection problems.

In this study, the framework of feasible regions of relative weights was adopted. Firstly, allowing the feasible region to include tolerance deviations of the fuzzy ratios, we define fuzzy consistency as theexistence of relative weights within the region. Secondly, we devise a maximum/minimum set ranking method to derive a crisp ranking from the global fuzzy weights (Noci and Toletti, 2000 [16]; 
Leung and Cao 2000)[17], The following steps of Fuzzy AHP proposed by Chang (1996)[18] have been utilized selecting purchases in the multi-period phase .

According to the method of Chang's extent analysis, each object is taken and extent analysis for each goal is performed respectively. Therefore $m$ extent analysis values for each object can be obtained, with the ,following signs :

$$
M_{\mathrm{gi}}^{1}, M_{\mathrm{gi}}^{2}, \ldots M_{\mathrm{gi}}^{m}, i=1,2, \ldots, n
$$

Where $M_{\mathrm{gi}}^{j}(j=1,2, \ldots, m)$ all are TFNs. The steps of Chang's extent analysis (Chang, 1996)[18] can be given as in the following:

Step 1 : The value of fuzzy synthetic extent with respect to the ith object is defined as

$$
\mathrm{S}_{\mathrm{i}}=\sum_{j=1}^{m} M_{\mathrm{gi}}^{j} \otimes\left[\sum_{i=1}^{n} \sum_{j=1}^{m} M_{\mathrm{gi}}^{j}\right]^{-1}
$$

To obtain $\sum_{j=1}^{m} M_{\mathrm{gi}}^{1}$, the fuzzy addition operation of $\mathrm{m}$ extent analysis values for a particular matrix is performed such as

$$
\sum_{j=1}^{m} M_{\mathrm{gi}}^{j}=\left(\sum_{j=1}^{m} l_{j}, \sum_{j=1}^{m} m_{j}, \sum_{j=1}^{m} u_{j}\right)
$$

And to obtain $\left[\sum_{i=1}^{n} \sum_{j=1}^{m} M_{\mathrm{gi}}^{j}\right]$, by performing the fuzzy addition operation of $M_{\mathrm{gi}}^{j}(j=1,2, \ldots, m)$ such that

$$
\left[\sum_{i=1}^{n} \sum_{j=1}^{m} M_{\mathrm{gi}}^{j}\right]^{-1}=\left(\sum_{j=1}^{m} l_{j}, \sum_{j=1}^{m} m_{j}, \sum_{j=1}^{m} u_{j}\right)
$$

And $\left[\sum_{i=1}^{n} \sum_{j=1}^{m} M_{\mathrm{gi}}^{j}\right]^{-1}$ can be calculated by the inverse of Eq.(3), as follows :

$$
\left[\sum_{i=1}^{n} \sum_{j=1}^{m} M_{\mathrm{gi}}^{j}\right]-1=\left(\frac{1}{\sum_{i=1}^{n} u_{i}}, \frac{1}{\sum_{i=1}^{n} m_{i}}, \frac{1}{\sum_{i=1}^{n} l_{i}}\right)
$$

Step 2 : as $M_{1}=\left(l_{1}, m_{1}, u_{1}\right)$ and $M_{2}=\left(l_{2}, m_{2}, u_{2}\right)$ are two triangular fuzzy numbers, the degree of possibility of $M_{2}=\left(l_{2}, m_{2}, u_{2}\right) \geq M 1=\left(l_{1}, m_{1}, u_{1}\right)$ is defined as

$$
\begin{gathered}
\mathrm{V}\left(\mathrm{M}_{2} \geq \mathrm{M}_{1}\right)=\sup \left[\min \left(\mu M_{1}(x), \mu M_{2}(y)\right)\right] \\
\mathrm{y} \geq x
\end{gathered}
$$

and can be expressed as follows :

$$
\mathrm{V}\left(\mathrm{M}_{2} \geq \mathrm{M}_{1}\right)=\operatorname{hgt}\left(\mathrm{M}_{1} \cap \mathrm{M}_{2}=\mu_{\mathrm{M}_{2}}(\mathrm{~d})\right.
$$




$$
=\left\{\begin{array}{cc}
1 & \text { ifm } m_{2} \geq m_{1} \\
0 \quad & \text { ifl } l_{1} \geq u_{2} \\
\frac{\left(l_{1}-u_{2}\right)}{\left(m_{2}-u_{2}\right)-\left(m_{1}-l_{1}\right)} \text { otherwise }
\end{array}\right\}
$$

Fig.2 illustrates Eq. (6) where $d$ is the ordinate of the highest intersection point D between $\mu_{\mathrm{M}_{1}}$ and $\mu_{\mathrm{M}_{2}}$. To compare $M 1=\left(l_{1}, m_{1}, u_{1}\right)$ and $M_{2}=\left(l_{2}, m_{2}, u_{2}\right)$, we need both the values of $\mathrm{V}\left(\mathrm{M}_{1} \geq \mathrm{M}_{2}\right)$ and $V\left(M_{2} \geq M_{1}\right)$.

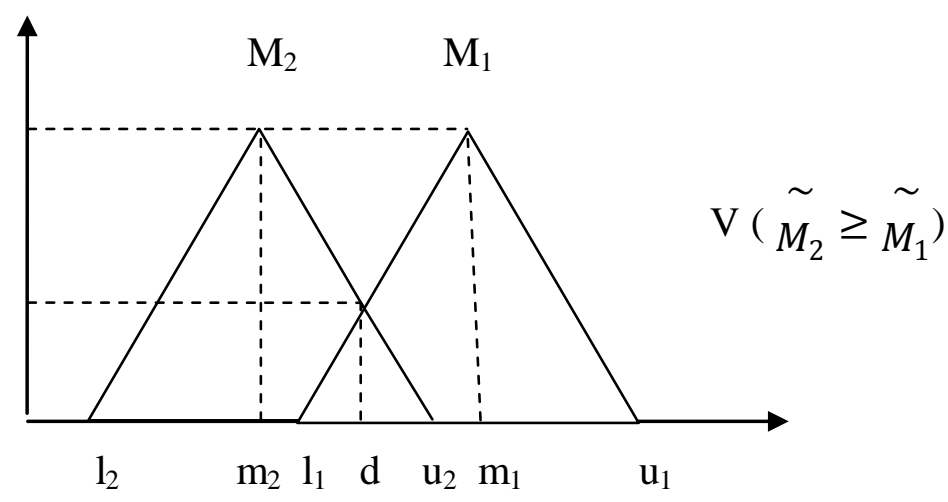

Fig. 2 : Intersection between $M_{1}$ and $M_{2}$ (Kahraman et al., 2004)

Step 3 : The degree possibility for a convex fuzzy number to be greater than $k$ convex fuzzyM $\mathrm{M}_{\mathrm{i}}(\mathrm{i}=$ $1,2, \ldots, \mathrm{k})$ numbers can be defined by

$$
\begin{aligned}
\mathrm{V}(\mathrm{M} & \left.\geq \mathrm{M}_{1}, \mathrm{M}_{2}, \ldots \mathrm{M}_{\mathrm{k}}\right)=v\left[\left(M \geq M_{1}\right) \operatorname{and}\left(M \geq M_{2}\right) \operatorname{and}\left(M \geq M_{k}\right)\right] \\
& =\min v\left(M \geq M_{1}\right), i=1,2, \ldots, k
\end{aligned}
$$

Assume that

$$
\mathrm{d}\left(A_{i}\right)=\min V\left(S_{i} \geq S_{k}\right) \text { for } k=1,2, \ldots, n ; k \neq i
$$

Then the weight vector is given by

$$
w=\left(\mathrm{d}\left(A_{1}\right), \mathrm{d}\left(A_{2}\right), \ldots, \mathrm{d}\left(A_{n}\right)\right)^{T}
$$

Where $A_{i}(i=1,2, \ldots, n)$ are the $n$ elements.

Step 4 : Via normalization, the normalized weight vectors are

$$
w=\left(\mathrm{d}\left(A_{1}\right), \mathrm{d}\left(A_{2}\right), \ldots, \mathrm{d}\left(A_{n}\right)\right)^{T}
$$

Where $\boldsymbol{W}$ is a non- fuzzy number.

\section{An Illustrative Example :}


This numerical example presents a mathematical model to select alternative in a multi-period environment.

\subsection{Define the criteria for purchase selection}

The main objective is the selection of the best purchase in a dynamic environment. The decisionmakers can estimate the relative weights - ratios for each pair of alternatives under every attribute as well as the relative weights ratios for the attributes .Application of common criteria to all purchases makes objectives comparisons possible. The criteria considered here in selection of the best purchase in a dynamic environment are:

- Price ( Product cost, Transportation cost, Development \& tooling cost)

- Product (Quality, Installation ease, Life cycle, Characteristics)

- Place ( Lead time, Distance)

- Promotion (Guarantee, Flexibility of service)

The hierarchy of the selection criteria and decision alternatives (i.e., purchases) in dynamic environment can be seen in Fig. 3. In the hierarchy, the overall objective (i.e., the best purchase) is placed at level 1 , criteria at level 2 , and the purchases alternatives at level 3.

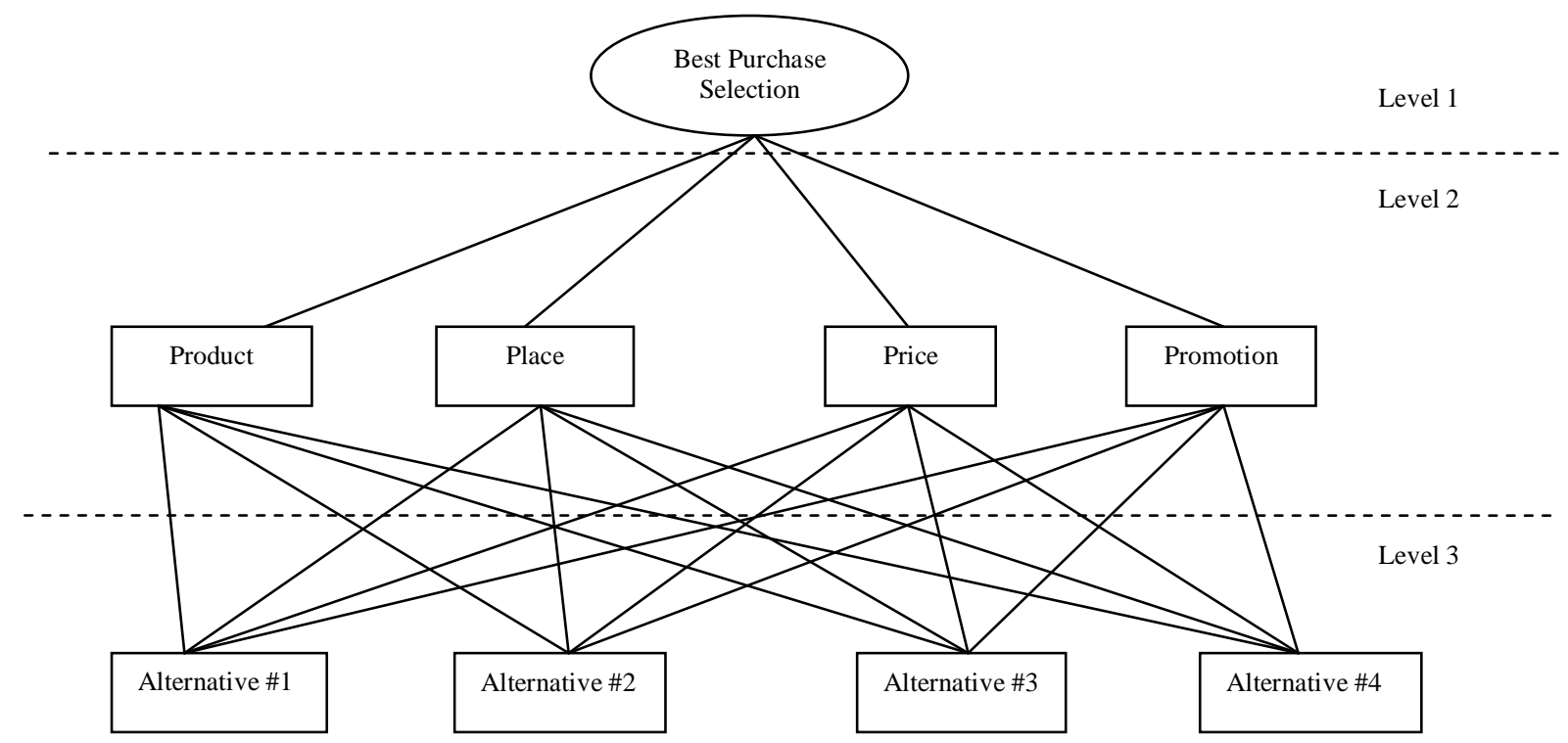

Figure 3: Hierarchy for purchase selection

The above mentioned criteria help in deciding the best selection in Customer`s Purchasing Decisionmaking Process (CPDP). The preferences of one over other have been decided by the decisionmakers. The human judgment may not always be crisp and hence the evaluation scale, used by decision-makers, is illustrated in Table 1 . 
Basirat Baygi.Mojtaba, Emam.Seyed Reza/ TJMCS Vol .2 No.4 (2011) 619-630

\section{Table 1: FAHP scale}

\begin{tabular}{|c|c|}
\hline Definition & Intensity of importance \\
\hline Equal & $(1,1,1)$ \\
\hline Weak & $(2 / 3,1,3 / 2)$ \\
\hline Fairly strong & $(3 / 2,2,5 / 2)$ \\
\hline Very strong & $(5 / 2,3,7 / 2)$ \\
\hline Absolute & $(7 / 2,4,9 / 2)$ \\
\hline
\end{tabular}

The fuzzy pair wise reciprocal judgments matrix by the decision-maker for each criterion, with respect to overall objective (i.e., selecting the best purchase; (see Table 2), and for each purchase with each of the criterion (see Tables 3-6), are determined in each of the three periods by the help of FAHP scale defined in Table 1.

Table 2: The Criterion fuzzy pair wise comparison matrix.

\begin{tabular}{|c|c|c|c|c|}
\hline & Product & Place & Price & Promotion \\
\hline Product & $(1,1,1)$ & $(5 / 2,3,7 / 2)$ & $(3 / 2,2,5 / 2)$ & $(3 / 2,2,5 / 2)$ \\
\hline Place & $(2 / 7,1 / 3,2 / 5)$ & $(1,1,1)$ & $(2 / 5,1 / 2,2 / 3)$ & $(2 / 3,1,3 / 2)$ \\
\hline Price & $(2 / 5,1 / 2,2 / 3)$ & $(3 / 2,2,5 / 2)$ & $(1,1,1)$ & $(3 / 2,2,5 / 2)$ \\
\hline Promotion & $(2 / 5,1 / 2,2 / 3)$ & $(2 / 3,1,3 / 2)$ & $(2 / 5,1 / 2,2 / 3)$ & $(1,1,1)$ \\
\hline
\end{tabular}

Table 3: The alternatives fuzzy pair wise comparison matrix with respect to criteria Product.

\begin{tabular}{|l|c|c|c|c|}
\hline Product & Purchase 1 & Purchase 2 & Purchase 3 & Purchase 4 \\
\hline Purchase 1 & $(1,1,1)$ & $(2 / 3,1 / 2,3 / 2)$ & $(3 / 2,2,5 / 2)$ & $(3 / 2,2,5 / 2)$ \\
\hline Purchase 2 & $(2 / 3,1,3 / 2)$ & $(1,1,1)$ & $(2 / 5,1 / 2,2 / 3)$ & $(2 / 3,1,3 / 2)$ \\
\hline Purchase 3 & $(2 / 5,1 / 2,2 / 3)$ & $(3 / 2,2,5 / 2)$ & $(1,1,1)$ & $(2 / 5,1 / 2,2 / 3)$ \\
\hline Purchase 4 & $(2 / 5,1 / 2,2 / 3)$ & $(2 / 3,1,3 / 2)$ & $(3 / 2,2,5 / 2)$ & $(1,1,1)$ \\
\hline
\end{tabular}

Table 4: The alternatives fuzzy pair-wise comparison matrix with respect to criteria Place

\begin{tabular}{|l|c|c|c|c|}
\hline Place & Purchase 1 & Purchase 2 & Purchase 3 & Purchase 4 \\
\hline Purchase 1 & $(1,1,1)$ & $(2 / 9,1 / 4,2 / 7)$ & $(2 / 3,1,3 / 2)$ & $(2 / 5,1 / 2,2 / 3)$ \\
\hline Purchase 2 & $(7 / 2,4,9 / 2)$ & $(1,1,1)$ & $(3 / 2,2,5 / 2)$ & $(3 / 2,2,5 / 2)$ \\
\hline Purchase 3 & $(2 / 3,1,3 / 2)$ & $(2 / 5,1 / 2,2 / 3)$ & $(1,1,1)$ & $(2 / 3,1,3 / 2)$ \\
\hline Purchase 4 & $(3 / 2,2,5 / 2)$ & $(2 / 5,1 / 2,3 / 2)$ & $(2 / 3,1,3 / 2)$ & $(1,1,1)$ \\
\hline
\end{tabular}

Table5: The alternatives fuzzy pair-wise comparison matrix with respect to criteria Price

\begin{tabular}{|l|c|c|c|c|}
\hline Price & Purchase 1 & Purchase 2 & Purchase 3 & Purchase 4 \\
\hline Purchase 1 & $(1,1,1)$ & $(3 / 2,2,5 / 2)$ & $(3 / 2,2,5 / 2)$ & $(2 / 3,1,3 / 2)$ \\
\hline Purchase 2 & $(2 / 5,1 / 2,2 / 3)$ & $(1,1,1)$ & $(1,1,1)$ & $(3 / 2,2,5 / 2)$ \\
\hline Purchase 3 & $(2 / 5,1 / 2,2 / 3)$ & $(1,1,1)$ & $(1,1,1)$ & $(2 / 5,1 / 2,2 / 3)$ \\
\hline Purchase 4 & $(2 / 3,1,3 / 2)$ & $(2 / 5,1 / 2,2 / 3)$ & $(2 / 5,1 / 2,2 / 3)$ & $(1,1,1)$ \\
\hline
\end{tabular}


Basirat Baygi.Mojtaba, Emam.Seyed Reza/ TJMCS Vol .2 No.4 (2011) 619-630

Table6: The alternatives fuzzy pair-wise comparison matrix with respect to criteria Promotion

\begin{tabular}{|l|c|c|c|c|}
\hline Promotion & Purchase 1 & Purchase 2 & Purchase 3 & Purchase 4 \\
\hline Purchase 1 & $(1,1,1)$ & $(2 / 9,1 / 4,2 / 7)$ & $(2 / 3,1,3 / 2)$ & $(2 / 5,1 / 2,2 / 3)$ \\
\hline Purchase 2 & $(7 / 2,4,9 / 2)$ & $(1,1,1)$ & $(3 / 2,2,5 / 2)$ & $(3 / 2,2,5 / 2)$ \\
\hline Purchase 3 & $(2 / 3,1,3 / 2)$ & $(2 / 5,1 / 2,2 / 3)$ & $(1,1,1)$ & $(2 / 3,1,3 / 2)$ \\
\hline Purchase 4 & $(3 / 2,2,5 / 2)$ & $(2 / 5,1 / 2,2 / 3)$ & $(2 / 3,1,3 / 2)$ & $(1,1,1)$ \\
\hline
\end{tabular}

For identifying the computation procedures, the pair-wise judgments from the Table 3 are evaluated as follows:

Purchase $_{1 \text { product }}=(4.667,6,7.5) \otimes(1 / 20.00,1 / 18.00,1 / 14.267)=(0.2333,0.333,0.526)$

Purchase $_{\text {2product }}=(2.733,3.5,4.667) \otimes(1 / 20.00,1 / 18.00,1 / 14.267)=(0.137,0.194,0.327)$

Purchase $_{3 \text { product }}=(3.30,4,4.833) \otimes(1 / 20.00,1 / 18.00,1 / 14.267)=(0.165,0.222,0.339)$

Purchase $_{4 \text { product }}=(3.567,4.5,4.667) \otimes(1 / 20.00,1 / 18.00,1 / 14.267)=$

$(0.178,0.250,0.327)$

After determining these results, these fuzzy values are compared by using Eq. (7)

$V\left(\right.$ Purchase $_{1 \text { product }} \geq$ Purchase $\left._{2 \text { product }}\right)=1$

$V\left(\right.$ Purchase $_{1 \text { product }} \geq$ Purchase $\left._{3 \text { product }}\right)=1$

$V\left(\right.$ Purchase $_{1 \text { product }} \geq$ Purchase $\left._{4 \text { product }}\right)=1$

$V\left(\right.$ Purchase $_{2 \text { product }} \geq$ Purchase $\left._{1 \text { product }}\right)=0.402$

$V$ (Purchase 2product $_{2} \geq$ Purchase $\left._{3 \text { product }}\right)=0.853$

$V\left(\right.$ Purchase $_{2 \text { product }} \geq$ Purchase $\left._{4 \text { product }}\right)=0.727$

$V\left(\right.$ Purchase $_{3 \text { product }} \geq$ Purchase $\left._{1 \text { product }}\right)=0.484$

$V\left(\right.$ Purchase $_{3 \text { product }} \geq$ Purchase $\left._{\text {2product }}\right)=1$

$V$ (Purchase (product $\geq$ Purchase $\left._{4 \text { product }}\right)=0.851$

$V\left(\right.$ Purchase $_{4 \text { product }} \geq$ Purchase $\left._{1 \text { product }}\right)=0.528$

$V\left(\right.$ Purchase $_{4 \text { product }} \geq$ Purchase $\left._{2 \text { product }}\right)=1$

$V\left(\right.$ Purchase $_{4 \text { produc }} \geq$ Purchase $\left._{3 \text { product }}\right)=1$

Then priority weights are calculated by using Eq. (8):

$d\left(\right.$ Purchase $\left._{1 \text { product }}\right)=\min (1,1,1)=1$

$d\left(\right.$ Purchase $\left._{\text {2product }}\right)=\min (0.402,0.853,0.727)=0.402$

$d\left(\right.$ Purchase $\left._{3 \text { product }}\right)=\min (0.484,1,0.851)=0.484$

$d\left(\right.$ Purchase $\left._{4 \text { product }}\right)=\min (0.528,1,1)=0.528$

Therefore, the weight vector from Table 3 is calculated as :

$$
\boldsymbol{w}_{\text {product }}^{\text {purc hase }}=(1,0.402,0.484,0.528)
$$

After the normalization of these values priority weights with respect to criteria Product are calculated as :

$$
\boldsymbol{w}_{\text {product }}^{\text {purc hase }}=(0.414,0.167,0.200,0.219)
$$

The same systematic approach is considered for the other evaluations, and priority weights are expressed

Correspondingly in Tables 7 as follows. 


\subsection{Results}

As we can see the priority of product is important for all alternatives. We can also observe from the table 7 that the price is more important than the place and promotion.

Table 7: The priorities weights of Criteria

\begin{tabular}{|c|c|}
\hline Criteria & priorities weights \\
\hline Product & 0.47 \\
\hline Place & 0.15 \\
\hline Price & 0.25 \\
\hline Promotion & 0.14 \\
\hline
\end{tabular}

Table 9: The priorities weights of suppliers with respect to all criteria

\begin{tabular}{|c|c|c|c|c|}
\hline Criteria & Product & Place & Price & Promotion \\
\hline Purchase 1 & 0.48 & 0.31 & 0.38 & 0.00 \\
\hline Purchase 2 & 0.17 & 0.69 & 0.27 & 0.85 \\
\hline Purchase 3 & 0.35 & 0.00 & 0.00 & 0.00 \\
\hline Purchase 4 & 0.00 & 0.00 & 0.35 & 0.15 \\
\hline
\end{tabular}

Table 10 represents the priority weights of the four Alternatives

\begin{tabular}{|c|c|}
\hline Alternative & priorities weights \\
\hline 1 & 0.367 \\
\hline 2 & 0.370 \\
\hline 3 & 0.165 \\
\hline 4 & 0.109 \\
\hline
\end{tabular}

\section{Conclusions:}

Obviously, for different decision-makers the alternatives priorities weights may change. This paper

Proposes a dynamic approach based on Fuzzy AHP for purchase selection problems that can help us to reach an effective decision. By this way we can deal with the uncertainty and vagueness in the decision process.

\section{References:}

[1] Ji- eunCha ,SooyoungKim,YeonheeLee “ Application of multi dimensional scaling for marketing-mix modification: A case study on mobile phone category " Expert Systems with Applications 2008 Elsevier Ltd.

[2] kotler . Philip " Marketing Management " Millenium Edition , custom edition for university of phoenix , chapter 1 "Marketing In The Twenty-First Century" (C) 2001by Prentice-Hall, Inc. Tenth Edition.

[3] Mosad Zineldin and Sarah Philipson "Kotler and Borden are not dead: myth of 
Relationship marketing and truth of the 4Ps" School of Management and Economics ,Vaxjo University, Vaxjo, Sweden, Journal of Consumer Marketing, Emerald Group Publishing Ltd.

[4] Claudio Vignali “ Mc Donald's: "think global,act local" - the marketing mix " Principal Lecture, Manchester Metropolitan University ,Manchester , UK, emerald-library .

[5] Chun-An Chen "Information-Oriented Online Shopping Behavior in Electronic Commerce Environment " Department of Information Management, Nan- Ya Institute of Technology , Chung - Li , Taiwan , Journal of Software , vol.4 june 2009 pp.307 -315

[6] Mohebbi . shima and Shafaei . Rasoul "e-Supply network coordination : the design of intelligent agents for buyer - supplier dynamic negotiations " Department of Industrial Engineering, K.N.Toosi University of Technology , Tehran , Iran . J Intell Manuf Springer Science + Business Media , LLC 26 January 2010.

[7] IrajMahdavi - ShimaMohebbi · MahdiZandakbari ·Nam jae Cho - NezamMahdaviAmiri. "Agent-based web service for the design of a dynamic coordination Mechanism in supply networks" Department of Industrial Engineering ,Mazandaran University of Science and Technology, Babol , Iran . J Intell Manuf (2009) . Springer Science + Business Media, LLC 14 September 2008.

[8] Saroj Koul and Rakesh Verma, School of Business Acadia University Wolfville, NS, CANADA , " Dynamic Vendor Selection: A Fuzzy AHP Approch " Operations Management Group National Institute of Industrial Engineering (NITIE).

[9] Saaty, T.L. (1980). “ The Analytical Hierarchy Process ”. McGraw-Hill, New York, NY. [10] Barbarosoglu G., \& Yazgac, T., (1997). " An application of the analytic hierarchy process to the supplier selection problem". Production and Inventory Management Journal,38(1),14-21

[11] Bellman, R.E., \& Zadeh, L.A. (1970). “ Decision-making in a fuzzy environment ". Management Sciences, 17, 141-164.

[12] Zimmermann, H.J., (1991). “ Fuzzy Set Theory and Its Applications " . Kluwer Academic Publishers, Dordrecht.

[13] Buckley J.J., Feuring T., \& Hayashi Y., (2001). “ Fuzzy hierarchical analysis revisited ". European Journal of Operational Research, 129, 48-64.

[14] Zaim, S., Sevkli, M. and Tarim, M., (2003). “ Fuzzy Analytic Hierarchy Based Approach for Supplier Selection ", Journal of Euromarketing, 12(3/4), pp. 147-176.

[15] Chen, Chen-Tung, Ching-Torng Lin, and Sue-Fn Huang. (2006) " A fuzzy approach for supplier evaluation and selection in supply chain management", International Journal of Production Economics, 102 (2), 289-301.

[16] Noci, G., \& Toletti, G., (2000). " Selecting quality-based programmes in small firms: A comparison between the fuzzy linguistic approach and the analytic hierarchy process". International Journal of Production Economics, 67, 113-133. 
Basirat Baygi.Mojtaba, Emam.Seyed Reza/ TJMCS Vol .2 No.4 (2011) 619-630

[17] Leung, L.C., \& Cao, D., (2000). “ Theory and Methodology, on consistency and ranking of alternatives in fuzzy AHP". European Journal of Operational Research, 124, 102-113. [18] Chang D. (1996). " Application of the extent analysis method on fuzzy AHP ". European Journal of Operational Research, 95, 649-655. 